Revista Brasileira de Odontologia Legal - RBOL

\title{
Ética odontológica
}

\section{VULNERABILIDADE DE CRIANCCAS E ADOLESCENTES E OS CÓDIGOS DE ÉTICA DA SAÚDE NO BRASIL: UMM ESTUDO DE ANÁLISE DOCUMENTAL.}

\section{Vulnerability of children and adolescents and health ethics codes in Brazil: a document analysis study.}

\author{
Gustavo PECLAT ${ }^{1}$, Amanda Luysa Roriz PINTO ${ }^{1}$, Giovanna Severino da Silva \\ JAIME$^{2}$, Mariana Barbosa GUIMARÃES ${ }^{3}$, Francielle Nunes de Azevedo \\ ROMANOWSKI ${ }^{4}$, Mauro Machado do $\mathrm{PRADO}^{5}$, Leandro Brambilla \\ MARTORELL ${ }^{5}$.
}

1. Acadêmico(a), bolsista PBIC/FUNADESP UniEvangélica 2017-18, Curso de Odontologia, Centro Universitário de Anápolis, Goiás, Brasil.

2. Especialista em Odontopediatria. EAP, Goiânia, Goiás, Brasil.

3. Mestranda em Saúde Pública. Universidade do Chile, Santiago, Chile.

4. Mestranda do Programa de Pós-graduação em Odontologia, Centro Universitário UniEvangélica, Anápolis-GO, Brasil.

5. Professor Associado do Curso de Graduação em Odontologia. Faculdade de Odontologia. Universidade Federal de Goiás, Goiânia-GO, Brasil.

6. Professor do Programa de Pós-Graduação em Odontologia. Curso de Odontologia de Anápolis. Centro Universitário UniEvangélica, Anápolis-GO, Brasil.

Informação sobre o manuscrito

Recebido em: 27 Maio 2020

Aceito em: 28 Junho 2020
Autor para contato:

Francielle Nunes de Azevedo Romanowski.

Rua AV6 quadra 08, lote 10 Condomínio Residencial

AnaVille. Anápolis, Goiás, Brasil. CEP: 75102-030.

E-mail: francielleromanowski@hotmail.com.

\section{RESUMO}

Os códigos de ética buscam orientar por meio de princípios e traduzem, em um sistema de valores, a moral e a missão de uma determinada profissão, e têm como seu ponto central a proteção e o zelo pela saúde e pela dignidade do paciente, individual e coletivamente considerado. Seu conteúdo deve ser pensado de forma a expressar valores essenciais assumidos por uma dada categoria para atuação digna a serviço da sociedade. O objetivo deste trabalho é analisar o conteúdo dos códigos de ética das profissões da área da saúde em relação à vulnerabilidade de crianças e adolescentes. Por meio da técnica de análise documental, nos códigos profissionais analisados, foram encontradas referências ao tema de forma bastante generalizada, inespecíficas quanto à sistematização de cuidados éticos e tutela a esta categoria de vulneráveis, remetendo à inferência de que os códigos deontológicos devem contemplar e procurar atentamente se atualizar quanto a temas contemporâneos e contundentes, como os direitos de crianças e adolescentes, dando maior suporte às ações dos profissionais que representam e cujas condutas norteiam.

\section{PALAVRAS-CHAVE}

Códigos de ética; Defesa da criança e do adolescente; Deontologia; Bioética. 


\section{INTRODUÇÃO}

Os códigos de ética buscam orientar por meio de princípios e traduzem, em um sistema de valores, a moral e a missão de uma determinada profissão. Seu conteúdo deve ser pensado de forma a expressar valores essenciais assumidos por uma dada categoria para atuação digna a serviço da sociedade. Em geral, além dos aspectos que um dado grupo ou categoria considera como importantes para que seu membro possa interagir e trabalhar, tais códigos buscam estar em consonância com a legislação vigente do país, com a Declaração Universal dos Direitos Humanos, as Leis Trabalhistas e outras previsões normativas ${ }^{1}$.

As normas de cada profissão são elaboradas com o objetivo de: enaltecê-la, orientar (quanto a direitos) e disciplinar (quanto a deveres) os profissionais, bem como proteger a categoria como um todo e as pessoas que dependem daquele profissional, ou seja, a sociedade, para que seja prestado um serviço em assistência idônea, responsável e com fim nobre. No entanto, há muitos aspectos que ainda não são abordados especificamente e que fazem parte do necessário comprometimento do profissional em ser eticamente correto ${ }^{2}$.

Os profissionais da área da saúde têm um papel social de extrema importância e, cotidianamente, em suas práticas, deparam-se com desafios técnicos e éticos, como aspectos que devem vir em paralelo no contexto da assistência em saúde. Para contribuir com a discussão e enfrentamento dos problemas éticos, os conselhos profissionais publicam e, periodicamente, revisam os códigos de ética das profissões, estabelecendo normativas e diretrizes para o agir profissional. Em geral, estas normas visam balizar a relação profissional de saúde-paciente, demonstrando interesse na proteção dos mais frágeis ${ }^{3}$.

Pensando no ciclo de vida, identificam-se dois grupos de interesse para este trabalho - as crianças e os adolescentes que, segundo o Estatuto da Criança e do Adolescente, são, respectivamente, pessoas de até doze anos de idade incompletos, e entre doze e dezoito anos de idade ${ }^{4}$. Para estes grupos, ainda existem as classificações de absolutamente incapazes (menores de 16 anos), relativamente incapazes (entre $16 \mathrm{e}$ 18 anos), no Código $\mathrm{Civil}^{5}$; e de penalmente inimputáveis (menores de 18 anos), no Código Penal ${ }^{6}$.

Atualmente, a aceitação da criança e do adolescente como parte ativa da sociedade vem crescendo cada vez mais, visto que a infância e a adolescência vêm assumindo, definitivamente, seu papel perante esta, como pessoas com autonomia em construção, mas a serem consideradas, ouvidas em seus interesses, vontades e valores. No passado, as crianças eram vistas como incapazes de ver e descrever seu próprio mundo ${ }^{7}$.

A maneira como as profissões de ensino superior organizam seus códigos de ética profissional, em especial, quando abordam (ou não) as crianças $e$ adolescentes, pode influenciar na construção da relação profissionalpaciente, podendo contribuir para relações mais humanizadas e adequadas a este público. O objetivo deste trabalho é 
analisar o conteúdo dos códigos de ética das profissões da área da saúde vigentes em relação às suas considerações sobre a vulnerabilidade de crianças e adolescentes.

\section{MATERIAL E MÉTODOS}

Esta é uma pesquisa documental na qual se analisam e destacam apenas determinados capítulos ou artigos dos códigos de ética de profissões da área da saúde em que os enfoques sejam os cuidados com os vulneráveis, em específico para esta análise, crianças e adolescentes.

Foram incluídos para análise os 14 códigos de ética profissional das profissões de ensino superior da área da saúde, segundo definição do Conselho Nacional de Saúde $^{8}$ (CNS, 1998): Assistentes Sociais ${ }^{9}$; $\quad$ Biólogos $^{10}$; Biomédicos ${ }^{11}$; Profissionais de Educação Física ${ }^{12}$; Enfermeiros ${ }^{13}$; $\quad$ Farmacêuticos ${ }^{14}$; Fisioterapeutas ${ }^{15}$; $\quad$ Fonoaudiólogos $^{16}$; Médicos ${ }^{17}$; Médicos Veterinários ${ }^{18}$; Nutricionistas ${ }^{19}$; $\quad$ Odontólogos $^{20}$; Psicólogos $^{21} ; \quad$ e $\quad$ Terapeutas Ocupacionais $^{22}$., cujo ano de publicação vigente encontra-se no Quadro 1. Por não se encontrar menção à relação direta com o cuidado a outro ser humano, excluiu-se o código de ética da Medicina Veterinária.

Dessa forma, os códigos de ética das treze categorias profissionais foram analisados por meio da técnica da análise de conteúdo, por apenas um pesquisador com formação em Bioética, tendo sido analisado no período de março a julho de 2018, com período de revisão de fevereiro a abril de 2020 por alterações parciais ou totais de alguns dos códigos analisados. Inicialmente, foi realizada uma leitura exploratória dos textos, seguidas das etapas de pré-análise, exploração do material, tratamento dos resultados, inferência e interpretação ${ }^{23}$.

\section{Quadro 1 - Ano de publicação dos códigos} de ética das profissões.

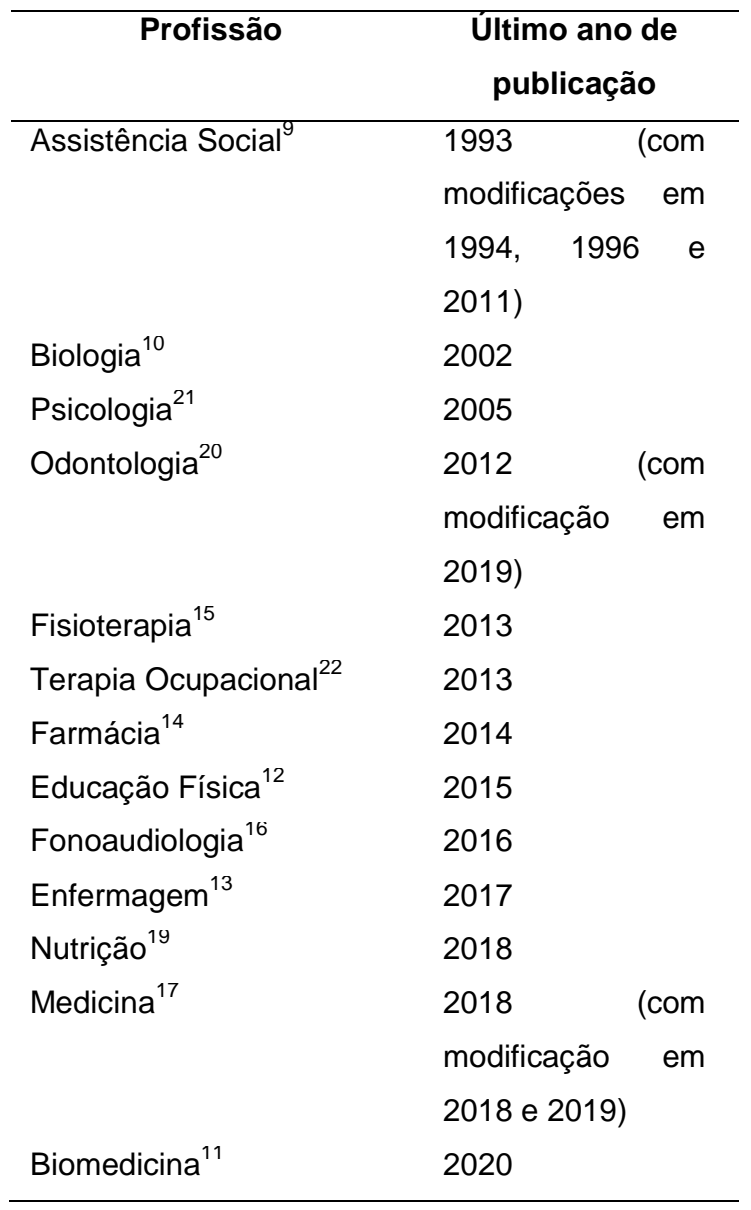

Metodologia semelhante já foi realizada por Narchi e Secaf $(2002)^{24}$, em que códigos de ética das profissões da saúde foram analisados por meio de leitura e releitura, seguidos de seleção do conteúdo de interesse e do agrupamento por similaridade em relação à temática de pesquisa científica (na ocasião, direitos autorais e do ser humano).

Não houve submissão do projeto de pesquisa ao Comitê de Ética em Pesquisa porque os dados analisados não 
envolvem direta ou indiretamente seres humanos, estando em análise apenas as resoluções publicadas pelos conselhos profissionais mencionados acima.

\section{RESULTADOS E DISCUSSÃO}

Após as etapas de análise foi possível criar quatro categorias para exposição dos resultados: aspectos gerais; dos desígnios; autonomia versus heteronomia; direito à privacidade e ao sigilo.

\section{Aspectos gerais}

A análise detalhada de cada um dos treze códigos de ética das profissões citadas evidenciou que, em nenhum deles, há um capítulo específico sobre atenção às crianças e aos adolescentes, que determine ou oriente qual deve ser a conduta ética no manejo destes pacientes.

Identificou-se que não há relação entre a data de publicação e a inclusão de referência à vulnerabilidade, pois até mesmo os códigos de ética que foram publicados mais recentemente, como os dos profissionais de Enfermagem ${ }^{13}$, Nutrição $^{19}$ e Medicina $^{17}$, não fazem considerações robustas aos cuidados dos pacientes que são crianças ou adolescentes, apesar de apontamentos ressaltando a inovação da Medicina ao incluir a temática de pesquisa envolvendo criança em sua última reformulação ${ }^{25}$.

Ressalta-se que nos códigos de ética dos profissionais de Assistente Social $^{9}, \quad$ Biólogo $^{10}, \quad$ Biomédico $^{11}$ e Profissionais de Educação Física ${ }^{12}$ não há menção direta ou indireta ao relacionamento dos profissionais com crianças e adolescentes, em manifesto descompasso com as elaborações de cuidado ético para com este grupo de vulneráveis e até mesmo em desatenção a preceitos legais hodiernos.

\section{Dos desígnios}

A figura das crianças e adolescentes aparece nos códigos de ética de duas formas. Na primeira, nota-se a citação direta a termos tradicionalmente relacionados a este público, de modo mais generalista, como no termo "incapazes", e de modo mais específico, como nos termos "menor" e "crianças e adolescentes", propriamente ditos. Na segunda, percebese a referência às crianças e adolescentes de modo indireto por meio de referência à figura daquele que Ihe cuida, ou seja, do seu “responsável legal” - Quadro 2.

Quando expressões relacionadas à incapacidade aparecem, fazem referência àqueles que são considerados como inabilitados a tomar decisões e a agir, tendo em vista o que é melhor para si, seja devido a pouca idade ou àqueles indivíduos que possuem alguma limitação mental $^{23}$. A noção de capacidade ou incapacidade aparece nos códigos de ética aqui estudados em contextos como: impossibilidade de início de tratamento sem autorização do responsável legal; proteção contra a retirada de órgãos para doação; cuidado de não exposição e sigilo.

O conceito de capacidade tem relação direta com a vida civil, sendo considerado também como um "termo psicológico que descreve um conjunto de habilidades mentais que as pessoas necessitam em suas vidas cotidianas 
(memória lógica, capacidade de cuidar de si mesmo etc.)"26.

Em seu desdobramento prático, o conceito de capacidade é útil para que se possa compreender a validade das ações tomadas na vida civil, para tanto, a legislação brasileira exige que o indivíduo esteja em plena posse de seus direitos, estabelecendo condições ou hipóteses que, uma vez resolvidas, fazem reconhecer ao indivíduo direitos ou a possibilidade de exercício pessoal destes direitos ${ }^{27}$.

Dessa forma, segundo o Código Civil Brasileiro, os menores de dezesseis anos são absolutamente incapazes de exercer pessoalmente os atos da vida civil; são "incapazes, relativamente a certos atos ou à maneira de exercê-los, os maiores de dezesseis e menores de dezoito anos"27.

Quadro 2 - Desígnio utilizado pelos códigos de ética das profissões.

\begin{tabular}{|c|c|c|}
\hline Profissão & Desígnio generalista & Desígnio específico \\
\hline Assistência $\quad$ Social $^{9}$, & & \\
\hline Biologia $^{10} \mathrm{e}$ & --- & --- \\
\hline \multicolumn{3}{|l|}{ Educação Física ${ }^{12}$} \\
\hline Psicologia ${ }^{21}$ & Responsável legal & Criança e adolescente \\
\hline Nutrição ${ }^{19}$ & Representante legal & Criança e adolescente \\
\hline Enfermagem $^{13}$ & Representante e responsável legal & Criança e adolescente \\
\hline Medicina $^{1 /}$ & Incapaz e representante legal & $\begin{array}{c}\text { Criança, adolescente } \\
\text { e pais }\end{array}$ \\
\hline Odontologia 20 & Incapaz, responsável legal e representante legal & \\
\hline Fisioterapia $^{15}$ & $\begin{array}{l}\text { Incapaz, responsável legal, representante legal, } \\
\text { menor e incapaz }\end{array}$ & \\
\hline Terapia Ocupacional $^{22}$ & $\begin{array}{c}\text { Incapaz, responsável legal, representante legal e } \\
\text { menor }\end{array}$ & \\
\hline Fonoaudiologia $^{16}$ & Incapaz, responsável legal e representante legal & \\
\hline Farmácia $^{14}$ & Responsável legal e representante legal & --- \\
\hline Biomedicina ${ }^{11}$ & Representante legal & \\
\hline
\end{tabular}

\section{Já quando expressões}

relacionadas ao conceito de "responsável legal" aparecem, nota-se também uma preocupação com 0 aspecto legal da relação, uma vez que a referência é justamente às pessoas que, regra geral, são civilmente responsáveis pela autorização de atendimento à saúde das crianças e adolescentes.

Para além, o contexto suscita preocupação com a decisão tomada por esses responsáveis, já que o posicionamento destes nem sempre coincide com a vontade expressa ou não da criança ou adolescente, hoje muito mais atentos e perceptivos a contextos que lhes dizem respeito. O uso da expressão “responsável legal”, traz à tona a figura dos pais, em intervenção heterônoma, sem considerações diretas e específicas sobre a criança ou adolescente, aspecto que será aprofundado em categoria descrita a seguir. 
Em relação à expressão "menor", é um tanto óbvia a interpretação de que se refere aos menores de idade, contrapondose à noção de maioridade, em especial, pelo Código Penal. Entretanto, em uma perspectiva histórica é interessante ressaltar que a expressão era mais popular nas políticas públicas do país até a década de 1980, citando a nota de Sierra e Mesquita $(2006)^{28}$, observa-se que: "A percepção da criança e do adolescente como menor (...) concebia como um problema de patologia social a situação de jovens abandonados e delinquentes, tornando-os objeto da política social".

Com a crescente organização da sociedade civil naquele contexto histórico, lutou-se para que houvesse mudanças de perspectiva na legislação, desse modo: "A nova lei alterou essa interpretação ao empregar a concepção de crianças e adolescentes como sujeito de direitos, adotando a doutrina da proteção integral, que passava a conceder segurança jurídica a esse público" ${ }^{28}$.

Além disso, a expressão menor, segundo Leone $(2009)^{29}$, revela um entendimento de que "todos os menores estão em uma mesma condição: a de incapacidade, criando a necessidade de se ter figuras aptas a decidir e responder por eles, como se estas figuras fossem sempre e inevitavelmente imbuídas das melhores intenções em relação à criança e ao adolescente".

Nos códigos profissionais da Fisioterapia ${ }^{15}$, Nutrição $^{19}$ e Terapia Ocupacional $^{22}$, há citações que usam a expressão "menor" como referência direta às crianças e adolescentes. $O$ que representa construção positiva, mas ainda incipiente em sua necessária abordagem crítica de respeito a este grupo de pacientes.

\section{Da autonomia versus heteronomia}

Em perspectiva etimológica, autonomia pode ser definida como "auto governo" e heteronomia como "governo por outros", termos frequentemente utilizados para se referir aos países que eram independentes ou governado por terceiros, respectivamente. Quando se pensa na autonomia de indivíduos compreende-se que poderão ser autônomos aqueles indivíduos com capacidade de agir intencionalmente e com liberdade sobre sua própria vida, em regra geral, no contexto aqui apresentado, os pais possuem autonomia para decidir sobre suas escolhas, mas fazem escolhas semelhantes para aspectos que repercutem na vida dos filhos, enquanto crianças e adolescentes, estas últimas, portanto, são consideradas decisões heterônomas ${ }^{30}$.

No Brasil, do ponto de vista legal, os pais, que habitualmente são os tutores/responsáveis legais que possuem o poder familiar $^{31}$ - ou seja, aquilo que é necessário para autorizar ou negar os atos praticados por profissionais da saúde. Entretanto, independentemente da motivação ou contexto, não há como haver garantias a priori de que essas decisões visarão o melhor para o interesse da criança.

Observa-se no caso desses pacientes a submissão "à heteronomia de seu tutor, em representação legal [mas, 
nem sempre legítima], visto que, embora existam processos de tomada de decisão conjunta, estes ainda têm tido pouco espaço nas práticas atuais no Brasil, principalmente pela ausência de respaldo legal consistente"26. Desta forma, quando tentados, são ainda carecedores de segurança jurídica para um exercício plural, inclusivo e responsável dos menores no contexto de deliberações que Ihes interessem.

Outro fator importante no que diz respeito à tomada de decisão por parte das crianças e adolescentes é que "a falta de dispositivos legais legitimadores $\mathrm{da}$ participação efetiva de crianças e adolescentes no processo de decisão e o paternalismo (...) são enormes empecilhos para a garantia da autonomia desses indivíduos. Quando há conflito entre os pais e a criança a respeito da continuidade do processo terapêutico, os profissionais geralmente respeitam a decisão dos pais em detrimento das crianças" ${ }^{26}$.

Em pesquisa realizada por Teixeira $(2005)^{32}$, é demonstrado que menores de idade representaram um terço dos pacientes-alvo de pesquisas para novos medicamentos realizadas por laboratórios estrangeiros no Brasil, em 2001. Essas crianças e adolescentes, em especial nos países em desenvolvimento, estão sujeitas a determinações por parte de pesquisadores e/ou mesmo de pais e familiares, que, por vezes, sequer informam ao indivíduo sobre sua participação nessas pesquisas. Apenas a partir da vigência da resolução n. 466/2012 do Conselho Nacional de Saúde $^{8}$ que regulamenta a pesquisa com seres humanos no Brasil é que se iniciou a exigência de um processo de assentimento livre e esclarecido voltado para crianças, adolescentes ou incapazes que, também devem firmar a sua autorização em participar da pesquisa em um termo específico, em linguagem acessível e adequado ao seu desenvolvimento cognitivo e psicológico ${ }^{33}$.

Neste contexto de pesquisa entende-se que $o$ assentimento do menor se fundamenta na assunção de que, mesmo nas hipóteses em que não tem capacidade legal para consentir, detém certo nível de compreensão e sua vontade de participar deve ser levada em conta, o que se amolda aos modelos que fundamentam a capacidade sanitária ${ }^{34}$.

Aponta-se para a restrição da criança ou adolescente somente receber tratamento mediante a autorização de seu responsável legal nos códigos da Odontologia $^{20}$ e Fonoaudiologia $^{16}$, aparecendo a ressalva de se poder intervir em casos de urgência/emergência quando tal anuência não for contextual e/ou tempestivamente possível somente no da Odontologia.

No código da Enfermagem ${ }^{13}$ percebe-se consonância com os estatutos de proteção às crianças e adolescentes, ressaltando que, nos casos de violência, em suas diferentes formas, os profissionais estão obrigados a realizar a notificação compulsória destes eventos, mesmo sem a autorização dos responsáveis. Ainda que estejam amparados legalmente no que diz respeito à notificação de abuso a crianças e adolescentes, os profissionais não deixam de viver os dilemas dessa decisão, 
devendo tomá-la de forma crítica e à autoridade devida.

$\mathrm{Na}$ relação profissional-paciente ou até mesmo de pesquisador e participante da pesquisa, mais complexo do que definir objetivamente se um paciente é autônomo ou não é compreender se o paciente é capaz de tomar uma decisão autônoma. A mudança do "ser autônomo" para o "agir autônomo" é mais realista na medida em que se reconhece que até mesmo pessoas que são tidas comumente como autônomas podem estar em situações em que não tenham capacidade de decidir no que seria considerado um padrão ideal de autonomia, por exemplo, por falta de informação ou habilidade para compreender a mesma. Do contrário, crianças e adolescentes, poderão demonstrar ter competência para tomar algumas decisões sobre aspectos de suas próprias vidas - realizar esse discernimento é o principal desafio dos profissionais que pretendem um cuidado mais respeitoso com os interesses desses pacientes ${ }^{30}$.

\section{Do direito à privacidade e ao sigilo}

Quando se pensa na perspectiva da privacidade conectada ao sigilo, gerando a obrigação de confidencialidade por parte dos profissionais, não há contestações sobre a necessidade de que as informações sanitárias das crianças e adolescentes sejam mantidas em segredo, o aspecto principal, portanto, ancora-se na seguinte questão: "até que idade ou em quais circunstâncias os profissionais de saúde podem revelar aos pais as informações confidenciais da criança ${ }^{35}$.
O código da Psicologia ${ }^{21}$ demonstra maior zelo com a autonomia das crianças e adolescentes, pois, ainda que ressalte 0 aspecto legal da necessidade de autorização dos pais ou responsáveis legais para início do tratamento, demarca também a importância de se restringir o compartilhamento de informações aos pais, revelando a estes somente o que for necessário para a melhor condução do caso - o que consiste em válido exercício de tutela e deferência à privacidade do menor.

Segundo Almeida et al. $(2015)^{36}$, muitos estudos apontam para o fato de que adolescentes "retardam a busca de auxílio médico, pois, receiam que o teor de seus relatos na consulta a um profissional seja revelado a familiares". Isso leva à análise do quão importante são esses aspectos citados nos códigos profissionais da saúde, “(...) já que esses pacientes, sabendo que terão suas informações expostas, podem não querer relatar seus problemas de saúde, ou omitir informações importantes para o adequado diagnóstico e tratamento (...)".

Em estudo bibliográfico e documental com propósito de analisar os contornos do exercício do direito à intimidade de adolescentes em atendimentos médicos no Brasil, Barbosa e Schiocchet $(2018)^{37}$ identificaram que "tanto o tratamento na deontologia médica quanto a teoria das incapacidades civilista carecem de maiores especificações para que se tornem diretrizes mais precisas de boas práticas no tocante à viabilização do exercício do direito à intimidade por adolescentes na relação médico-paciente". 
Para além dessa perspectiva marcada pelo regramento de legislações, e compreendendo o já mencionado potencial conflito de interesse entre pais e filhos, propõe-se como caminho alternativo. Entre a suspensão total da privacidade do paciente e o sigilo absoluto, a observação de cada caso, levando em conta os interesses e a capacidade do paciente de compreender a situação e a segurança dele, da sua família e daqueles de seu convívio. Para tanto, é importante que o profissional de saúde seja capaz de realizar esse discernimento, conheça a legislação específica e documente e discuta os casos com equipe multidisciplinar $^{38}$.

É interessante frisar que, em relação ao sigilo, ao mesmo tempo em que a Enfermagem ${ }^{13}$ e a Fonoaudiologia ${ }^{16}$ expressam o direito do incapaz ao sigilo, a Odontologia ${ }^{20}$ expressa, de modo contrário, a possibilidade de quebra de sigilo do incapaz ao responsável como uma justa causa. Além disso, muitos códigos já se posicionavam favoravelmente à publicação de casos clínicos como material didático ou publicação científica mediante autorização de pacientes ou, no caso em tela de crianças e adolescentes, de seus responsáveis legais o que poderia de alguma forma representar uma quebra autorizada (de modo heterônomo) do sigilo profissional. Mais recentemente códigos como o da Fonoaudiologia ${ }^{16}$ e a Resolução n. 196/2019 do Conselho Federal de Odontologia ${ }^{39}$ passaram também, mediante a autorização dos pais, permitir a divulgação da imagem desses pacientes com fins comerciais. Mais detalhes sobre os aspectos de confidencialidade e sigilo profissional, no caso de crianças e adolescentes ou não, serão explorados em artigo futuro.

Também se destaca que a Código de Ética da Farmácia ${ }^{14}$ retira do incapaz a possibilidade do direito de decisão sobre seu tratamento, quando a incapacidade tenha sido atestada mediante laudo médico ou decisão judicial.

Por ser um estudo comparativo entre o que explicitam os códigos de ética das diferentes profissões da área da saúde sobre a conduta de atendimento a crianças e adolescentes, espera-se, como resultado, incitar o leitor à reflexão e ponderação sobre a necessidade de mudança de olhar para a assistência às crianças e adolescentes, de forma a primar por parâmetros de reciprocidade e interação, tanto quanto possível e responsável, em detida atenção para mitigar a interferência heterônoma que lhes pode afetar a dignidade.

Questiona-se quão insalubre, do ponto de vista moral, representa não haver real, crítica e contundente participação dos códigos de ética na formação ético-legal dos profissionais da saúde que realizam atendimento a criança e adolescentes.

\section{CONSIDERAÇÕES FINAIS}

Os códigos analisados, em regra geral, não fazem alusão direta e específica às crianças e adolescentes, não mencionando particularidades que podem afetar a relação profissional paciente nas relações de atenção à saúde ou pesquisa científica. Frequentemente as recomendações prescritas pelos códigos 
profissionais servem para os pacientes

que, comumente, são consideradas civilmente incapazes, ou seja, há nesses códigos uma abordagem que se aproxima da perspectiva legal.

Diante de uma leitura ética afirmativa, construtiva e emancipatória, sem deixar de ser responsável, considerase que todos os treze códigos devem se atualizar e buscar inserir em seu conteúdo perspectivas voltadas ao cuidado e direitos dos pacientes aqui estudados, buscando contemplar, de forma mais clara, cada um deles, em sua especificidade, deixando os sinônimos "menor", "incapaz" de lado, pois, estas expressões não representam adequadamente as nuances desses pacientes.
Uma crítica especial se faz ao Código de Ética Odontológica ${ }^{20}$, que se mostra contrário a qualquer forma de sigilo entre profissional e a criança ou adolescente, em uma perspectiva acrítica, postos os enunciados éticos de autonomia em construção para tais pacientes menores, obviamente a serem considerados de acordo com cada caso e contexto.

Vale ainda lembrar a omissão dos códigos profissionais do Assistente Social ${ }^{9}$, Biólogo $^{10}$ e Profissionais de Educação Física $^{12}$, que não fazem qualquer menção ao assunto, embora os profissionais daquelas áreas também lidem diretamente com o grupo de pacientes aqui debatido.

\section{ABSTRACT}

The codes of ethics seek to guide by means of principles and translate, in a system of values, the morals and the mission of a certain profession, and have as their central point the protection and zeal for health and dignity of the patient, individual and collectively considered. This content must be designed in order to express essential values assumed by a given category for a dignified performance in the service of society. The objective of this work is to analyze the content of the codes of ethics of health professions in relation to the vulnerability of children and adolescents. Through the technique of document analysis, in the analyzed professional codes, references to the theme were found in a very generalized way, unspecified regarding the systematization of ethical care and protection to this category of vulnerable, referring to the inference that the deontological codes must contemplate and seek attentively update itself on contemporary and forceful themes, such as the rights of children and adolescents, giving greater support to the actions of the professionals they represent and whose conduct guides.

\section{KEYWORDS}

Codes of ethics; Defense of children and adolescents; Deontology; Bioethics.

\section{REFERÊNCIAS}

1. Fortes PAC. Ética e saúde: questões éticas, deontológicas e legais, tomadas de decisões, autonomia e direitos dos pacientes, estudos de caso. São Paulo: EPU; 1998.

2. Schirmer J. Ética profissional. In: Oguisso T.; Zoboli ELCP. (Org.). Ética e bioética: desafios para a enfermagem e a saúde. Barueri-SP: Manole; 2006. p: 61-7.

3. Maurique JA. Conselhos: controle profissional, processo administrativo e judicial. In: FREITAS, V.P. (org.) Conselhos de Fiscalização Profissional. Doutrina e Jurisprudência. Prol Editora: São Paulo, 2009.
4. Brasil. Lei № 8.069 , de 13 de julho de 1990. Dispõe sobre o Estatuto da Criança e do Adolescente e dá outras providências. Disponível em: http://www.planalto.gov.br/ccivil 03/leis/l8 069.htm. Acesso em: 21 de maio de 2020.

5. Brasil. Código Civil (2002). Código civil brasileiro e legislação correlata. - 2. ed. Brasília: Senado Federal, Subsecretaria de Edições Técnicas, 2008. 616 p. Disponível em:

https://www2.senado.leg.br/bdst/bitstream/ handle/id/70327/C\%C3\%B3digo\%20Civil\% $202 \% 20$ ed.pdf. Acesso em: 19 de janeiro de 2020.

6. Brasil. Código penal. - Brasília: Senado Federal, Coordenação de Edições 
Técnicas, 2017. 138 p. Disponível em: https://www2.senado.leg.br/bdsf/bitstream/ handle/id/529748/codigo penal 1ed.pdf. Acesso em 14 de janeiro de 2020.

7. Gaiva MAM. Pesquisa envolvendo crianças: aspectos éticos. Revista Bioética. 2009; 17 (1):135-46.

8. Brasil. Ministério da Saúde. Conselho Nacional de Saúde. Resolução no 287, de 08 de outubro de 1998. Disponível em: http://conselho.saude.gov.br/resolucoes/re so $98 . \mathrm{htm}$. Acesso em: 24 de maio de 2020.

9. Brasil. Conselho Federal de Serviço Social. Lei 8.662/93 de regulamentação da profissão. - 10 a . ed. rev. e atual. [Brasília]: Conselho Federal de Serviço Social, [2012]. Disponível em: http://www.cfess.org.br/arquivos/CEP CF ESS-SITE.pdf. Acesso em 14 de janeiro de 2020.

10. Brasil. Conselho Federal de Biologia. Regulamenta o Código de ética do profissional biólogo Disponível em: http://www.crbio2.org.br/codigo etica.htm. Acesso em: 19 de janeiro de 2020.

11. Brasil. Conselho Federal de Biomedicina. Resolução n. 330, de 05 de novembro de 2020. Regulamenta o novo Código de Ética do Profissional Biomédico. Disponível em: https://www.in.gov.br/en/web/dou/rresolucao-n-330-de-5-de-novembro-de2020-286734436. Acesso em: 09 de novembro de 2020.

12. Brasil. Conselho Federal de Educação Física. Resolução CONFEF no 307/2015. Dispõe sobre o Código de Ética dos Profissionais de Educação Física registrados no Sistema CONFEF/CREFs. Disponível em: https://www.confef.org.br/confef/resolucoes 1381. Acesso em: 16 de janeiro de 2020.

13. Brasil. Conselho Federal de Enfermagem. Resolução Cofen no 564/2017. Regulamenta o código de ética do profissional de enfermagem. Disponível em: http://www.corengo.org.br/acesse-ebaixe-o-codigo-de-etica 15872.html. Acesso em 10 de janeiro de 2020.

14. Brasil. Conselho Federal de Farmácia. Resolução no 596 de 21 de fevereiro de 2014. Ementa: Dispõe sobre o Código de Ética Farmacêutica. Disponível em: https://crfsc.gov.br/codigo-de-eticafarmaceutica/. Acesso em 10 de janeiro de 2020.

15. Brasil. Conselho Federal de Fisioterapia. Resolução no424, de 08 de julho de 2013. (D.O.U. no 147, Seção 1 de 01/08/2013). Estabelece o Código de Ética e Deontologia da Fisioterapia. Disponível em:

http://www.coffito.org.br/conteudo/con vie w.asp?secao $=26$. Acesso em: 10 de janeiro de 2020.

16. Brasil. Conselho Federal de Fonoaudiologia. Aprova o código de ética dos profissionais de fonoaudiologia na 145a Sessão Plenária Ordinária de 18 de Fevereiro de 2016 e regulamenta a Resolução CFFa no 490/2016, publicada no Diário Oficial da União, Seção 1, páginas 196 a 198, dia 07/03/2016. Disponível em: https://www.fonoaudiologia.org.br/cffa/inde x.php/codigo-de-etica/. Acesso em: 12 de janeiro de 2020.

17. Brasil. Código de Ética Médico: Resolução CFM no 2.217, de 27 de setembro de 2018, modificada pelas Resoluções CFM $\mathrm{n}^{\circ}$ 2.222/2018 e 2.226/2019 / Conselho Federal de Medicina - Brasília: Conselho Federal de Medicina, 2019. 108 p. $15 \mathrm{~cm}$. Disponível em: http://portal.cfm.org.br/images/PDF/cem20 19.pdf. Acesso em: 13 de janeiro de 2020.

18. Brasil. Conselho Federal de Medicina Veterinária. Resolução no 1138, de 16 de dezembro de 2016. Aprova o Código de Ética do Médico Veterinário regulamentado pela Resolução CFFa $\mathrm{n}^{\circ}$ 490/2016, publicada no Diário Oficial da União, Seção 1, páginas 196 a 198, dia 07/03/2016. Disponível em: http://portal.cfmv.gov.br/uploads/RESO $\% 2$ 01138 2016\%20C\%C3\%B3digo\%20de\% 20\%C3\%89tica\%20do\%20M\%C3\%A9dic 0\%20Veterin\%C3\%A1rio.pdf. Acesso em: 12 de janeiro de 2020.

19. Brasil. Conselho Federal de Nutrição. Resolução CFN № 599, de 25 de fevereiro de 2018. Aprova o Código de Ética e de Conduta do Nutricionista. Disponível em: https://www.cfn.org.br/wpcontent/uploads/2018/04/codigo-deetica.pdf. Acesso em: 12 de janeiro de 2020.

20. Brasil. Conselho Federal de Odontologia. Revoga o Código de Ética Odontológica aprovado pela Resolução CFO-42/2003 e aprova outro em substituição. Resolução n. 118, de 11 de maio de 2012. Disponível em: $\quad$ http://cfo.org.br/wpcontent/uploads/2009/09/codigo_etica.pdf. Acesso em: 19 de janeiro de 2020.

21. Brasil. Conselho Federal de Psicologia. Resolução cfp no 010/05. Aprova o Código de Ética Profissional do Psicólogo. 2005. Disponível em: http://site.cfp.org.br/wpcontent/uploads/2012/07/codigo-de-eticapsicologia.pdf. Acesso em: 13 de janeiro de 2020.

22. Brasil. Conselho Federal de Terapia Ocupacional. Resolução nำ425, de 08 de julho de 2013. (D.O.U. no 147, Seção 1 de 01/08/2013). Estabelece o Código de Ética e Deontologia da Terapia Ocupacional. Disponível em: 
http://www.coffito.org.br/conteudo/con vie w.asp?secao $=45$. Acesso em: 19 de janeiro de 2020.

23. Bardin L. Análise de conteúdo. Lisboa: Edições 70; 2000.

24. Narchi NZ, Secaf V. Códigos de ética profissional e a pesquisa: direitos autorais e do ser humano. Rev Paul Enf. 2002; 21(3): 227-33.

25. Ferreira S, Porto D. Novo Código de Ética Médica, bioética e esperança. Rev Bioét. 2018; 26(4): 479-83. http://dx.doi.org/10.1590/198380422018264000.

26. Albuquerque R, Garrafa V. Autonomia e indivíduos sem a capacidade para consentir: o caso dos menores de idade. Rev Bioét. (Impr.). 2016; 24(3):452-8.

27. Brasil. Conselho Nacional de Saúde. Resolução no 466, de 12 de dezembro de 2012. Aprova as diretrizes e normas regulamentadoras de pesquisas envolvendo seres humanos. [Internet]. Diário Oficial da União. Brasília; 13 jun 2013.

28. Sierra VM, Mesquita WA. Vulnerabilidades e Fatores de Risco na Vida de Crianças e Adolescentes. São Paulo em Perspectiva. 2006; 20(1):14855.

29. Leone CA. Criança, o Adolescente e a Autonomia. Revista Bioética. 2009; 6(1): 01-4.

30. Beauchamp TL, Childress JF. Principles of Biomedical Ethics. 6th ed. Oxford University Press: New York. 2009.

31. Brasil. Lei n. 8.069, de 13 de julho de 1990. Dispõe sobre o Estatuto da Criança e do Adolescente e dá outras providências. Disponível em: http://www.planalto.gov.br/ccivil 03/LEIS/ L8069.htm\#art266. Acesso em: 22 de janeiro de 2020.

32. Teixeira VMF. Consentindo riscos na esperança de cura. O processo de consentimento em sujeitos de pesquisa: crianças, adolescentes e suas famílias. Dissertação (Mestrado). Fundação Oswaldo Cruz. Rio de Janeiro; 2005.

33. Brasil. Ministério da Saúde. Conselho Nacional de Saúde. Resolução no 466, de 12 de dezembro de 2012. Aprova as diretrizes e normas regulamentadoras de pesquisas envolvendo seres humanos.

34. Albuquerque A. Assentimento da criança para participar de pesquisa sob a ótica da sua capacidade sanitária. Rev.

Redbioética/UNESCO. 2016; 2 (14):19-30.

35. Eler K, Albuquerque A. Direitos humanos da paciente criança. Cad Ibero-amer Dir Sanit., 2019; 8(1): 1-163. http://dx.doi.org/10.17566/ciads.v8i1.509.
36. Almeida RA, Lins L, Rocha ML. Dilemas éticos e bioéticos na atenção à saúde do adolescente. Rev bioét (Impr.). 2015; 23 (2): 320-30.

37. Barbosa AS, Schiocchet, T. Tutela do direito à intimidade de adolescentes nas consultas médicas. Revista Brasileira de Direito Civil - RBD Civil. 2018; 15: 49-69.

38. Santos MFO, Santos TEO, Santos ALO. A confidencialidade médica na relação com o paciente adolescente: uma visão teórica. Rev Bioét. 2012; 20(2): 318-25.

39. Brasil. Conselho Federal de Odontologia. Resolução n. 196 de 29 de janeiro de 2019. Autoriza a divulgação de autoretratos (selfie) e de imagens relativas ao diagnóstico e ao resultado final de tratamentos odontológicos, e dá outras providências. DOU de 31/01/2019 (nº 22, Seção 1, pág. 91). Disponível em: http://www.lex.com.br/legis 27765499 RE SOLUCAO N 196 DE 29 DE JANEIRO DE 2019.aspx. Acesso em: 18 de junho de 2020. 